\title{
BESTIARUL ÎN OPERA LUI LUCIAN BLAGA ȘI A LUI VASILE VOICULESCU: CONTEXTE, DECORURI, SIMBOLURI
}

\author{
Adela - Diana CHINDRIȘ \\ Anul al III-lea, Universitatea de Vest din Timișoara
}

\begin{abstract}
The purpose of this paper is to reflect upon the ways the same animals depicted in Lucian Blaga's poetry and Vasile Voiculescu's respectively are shaped based on comparison. On the one hand, the animals in Blaga's works get a metaphorical pattern, while, on the other hand, those in Voiculescu's poetry keep the ordinary meaning. While in Voiculescu's case animals are part of the traditional setting, Blaga gives them symbolic and transcendental meanings.
\end{abstract}

Keywords: animals, beasts, mythology, setting, symbols, transcendency, tradition.

\section{Argument}

Bestiarul a fost înglobat în mod constant în mentalul colectiv și individual mai ales din perspective antropologico-folclorice, prin ,tendinţa omului de a asocia unor animale fabuloase propriile sale concepte morale, filozofice şi religioase [...] satisfăcută fie prin imaginarea unor fiinţe fantastice (balaur, cerber, inorog), fie prin exacerbarea puterilor şi calităţilor unor animale reale, pe care omul le ridica la rang de simbol"1. Individul a simţit nevoia, chiar din timpuri ancestrale, să valorifice într-un mod metaforic sau cât se poate de verosimil fiara de lângă el (sau, de ce nu, din el). De la artele plastice la literatură, creaturile au parcurs drumul unor contextualizări, devenind elemente ale decorului ori dobândind valențe de simbol. Literatura română, cu întregul său bagaj cultural, nu face excepție, nici măcar în poezie. Astfel, pornind de la figurile teriomorfe, lucrarea de față își propune să dezbată aspectele similare, respectiv distincte, în modul de abordare a creaturilor în lirica lui Lucian Blaga și a lui Vasile Voiculescu. Vom urmări contextele și cadrele în care sunt plasate câteva animale pentru a evidenția divergențele născute din atitudinile diferite ale celor doi scriitori față de necuvântător.

\section{Animalele în literatură}

Unul dintre punctele de început ale acestei lucrări îl reprezintă afirmaţia lui Andrei Oișteanu, conform căreia: „omul a acordat animalului o infinitate de ipostaze mitice, atribuindu-i puteri şi calităţi magice"2 odată ce își conștienizează și problematizează existenţa efemeră. În acest sens, dimensiunea animalică a fost adusă ca reprezentare în toate formele

\section{3}


imaginarului. Transpunerea ei în literatură a început încă din Antichitate, de la Epopeea lui Ghilgameș, și s-a conturat până în perioada contemporană, fiecare curent și cultură punând amprenta pe modul de reprezentare și de individualizare a animalului. Pe lângă propriile abordări ale scriitorilor, atât în literatura universală, cât și în cea română, au fost revitalizate diferite mituri, legende, credințe strămoșești pentru a crea avatarurile animaliere.

În ceea ce privește spațiul românesc, unul dintre primii scriitori care valorifică animalele este Dimitrie Cantemir. Procedeul pe care îl folosește cu precădere este alegoria, abstractizând ideile textuale, aspectul fiind foarte sesizabil în Istoria ieroglifică. În plus, acesta creează făpturi fabuloase prin hibridizarea și mixarea altora. Pe lângă opera lui Cantemir, trebuie amintite basmele, povestirile şi fabulele, care se folosesc de materialul bestiar în diferite moduri. Toate acestea coagulează un fond cultural care se transformă într-un topos literar frecvent. Ceea ce diferențiază reprezentările literare este felul în care această rețea a bestiarului este remodelată și transfigurată pentru a transfera imaginarului literar un ,vocabular simbolic"3.

Privind diacronic, putem spune că, treptat, teriomorful își stilizează chipurile, de la literatura medievală ce abundă în figuri baroce, grotești, la literatura postmodernă care vine să hibridizeze corporalitatea inclusiv prin ștergerea graniţelor dintre uman, animal și artificial, ajungând la post-uman, transuman. Abordând, în literatura română, perioada ,cea mai canonică”, cea interbelică, observăm că, prin cele două mari orientări (modernism și tradiţionalism), s-au produs texte diferite din punctul de vedere al semnificațiilor, chiar dacă în unele cazuri instrumentarul este același. Un bun exemplu în acest sens îl reprezintă dualitatea Lucian Blaga - Vasile Voiculescu. Pe de-o parte, amândoi prezintă animale comune în opera lor poetică, însă, pe de altă parte, modul în care acestea sunt valorificate diferă. Blaga optează pentru metaforizarea şi plasarea lor într-un cadru misterios, transcendent, pe când Voiculescu exploatează materialitatea și organicitatea animalelor, conferindu-le un cadru brutal sau chiar concret.

\section{Selecția animalieră}

Neavând pretenția exhaustivității, am selectat șase ipostaze animaliere prezente la cei doi poeți: șarpele, balaurul, ursul, cerbul, calul, inorogul/unicornul. Raţiunea acestei selecții se bazează, în primul rând, pe frecvența apariţiei acestor figuri în texte (în cazul lui Blaga: șarpele - de 23 de ori; balaurul - de 3 ori; ursul - de 10 ori; cerbul - de 14 ori; calul - de 8 ori; inorogul - de 3 ori, respectiv unicornul - de 7 ori), dar și pe convenționalitatea acestora, pentru că sunt printre cele mai uzitate, de fapt, în literatura populară, cu excepția inorogului.

\section{4}


Şarpele. Ne începem demersul cu imaginea șarpelui, comun în imaginarul creștin, folcloric, dar inclus şi într-o bogată literatură a fantasticului sau a fantasy-ului de azi. Plasarea acestuia la începutul studiului se explică atât prin notorietatea sa, cât și prin complexitatea simbolică. Fiind „legat de cele patru stihii ale naturii”4 (pământ, apă, foc, văzduh), acesta reprezintă un imago mundi, care incorporează esența universală.

Caracterul său complex mai constă și în dedublarea atitudinilor față de acesta în cultura universală. În acest sens, atât Blaga, cât și Voiculescu îi conferă acestuia o dublă valență: pozitivă, respectiv negativă. Din punctul de vedere al caracterului pozitiv, șarpele este asociat unei entităţi purtătoare de noroc, aspect sugerat în poezia lui Blaga, Monolog: „Norocul de aur [...]/ ți-1 dăruie șarpele casei și zeii din plai" ${ }^{5}$. Conform credințelor populare, șarpele casei aduce noroc la casă, ținând farmecele și relele departe de mediul domestic și a cărei dispariție este „sinonimă cu risipirea familiei, cu pierderea norocului, cu moarte întregului neam”6. Blaga revitalizează această credință populară asociind animalul cu divinităţile superioare.

Tot din prisma valenței sale pozitive, Voiculescu, la rândul său, asociază șarpele cu norocul omului. Poezia Pisica popii se bazează pe o altă credință populară conform căreia întrun anumit moment al existenței ,se strâng grămezi mai mulți șerpi și se bat, încep a sufla și se face o movilă de spumă deasupra căreia se alege piatra scumpă"7 . Acest ,produs” prețios simbolizează istețimea și norocul, în text luând forma unei omide. Instanța textuală, reprezentată de un copil, revelează măreția acestuia: „Am văzut cum mi-a căzut din cer zodia cu norocul!"8. Prin extrapolare, omida, rezultatul simbolic al luptelor mitice dintre șerpi, trimite la ideea de vitalitate potențială, de început al unei existențe. Astfel, șarpele este perceput ca

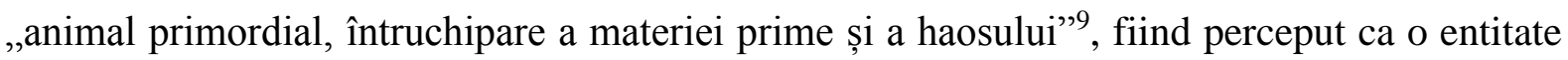
crucială universului.

Şarpele ca element generator apare și în opera blagiană. Astfel, poezia Legenda trimite la momentul ispitirii Evei. Pe de-o parte, șarpele apare ca entitate negativă, însă, pe de altă parte, capătă un rol crucial, simbolizând elemental declanșator, ajutând la conturarea lumii de dinafara Paradisului. Fructul blestemat oferit Evei constituie, în mod simbolic, geneza universului profan: „sâmburele se pierdu-n țărână, unde încolți./ Un măr crescu acolo - și alții îl urmară/ prin lungul șir de veacuri”'10. Caracterul vital al șarpelui este evidențiat și de către Voiculescu în poezia Din flori. Într-un decor în care natura găzduiește un moment de vitalitate maximă (nașterea unui copil pe un fond armonic în care diferite mamifere își protejează puii), șarpele joacă rolul de hrană: „Târziu zbură o barză la cuib c-un șarpe-n cioc”"11. În acest caz, șarpele se materializează, este inclus într-un decor animalier complex.

\section{5}


De observat, așadar, e faptul că Blaga optează pentru învăluirea șarpelui în mister, spre deosebire de Voiculescu, care optează pentru materializarea lui. În opera blagiană Eva, șarpele este prezentat ca fiind o entitate distinsă (,,ca un clopoțel de-argint”"12), misterioasă, inaccesibilă chiar și divinității (,Nici Dumnezeu n-a auzit, ce i-a șoptit anume,/ cu toate că a ascultat și el"13). De asemena, poezia Fiu al faptei nu sunt evidenţiază ipostaza șarpelui ca fiind elementul care aduce armonia dintre individ și lumea exterioară: „dar încolăcit la picioarele mele/ mascultă şi mă pricepe prea bine/ şarpele cel cu ochii de-a pururi deschişi// spre înţelepciunea de dincolo"14. Chiar dacă este plasat într-un cadru verosimil, în planul uman, încolăcirea lui trimite la ideea de dominare a rațiunii, căci șarpele este cel care înțelege nevoia de contemplare, de retragere din „fapte”, din acțiune și intrarea într-o pasivitate totuși creatoare.

La polul opus, Voiculescu concretizează animalul, după cum am susținut anterior. În poezia Șarpele, creatura dobândește diferite atribute din câmpul podoabelor: „un șarpe împodobit splendid,/ În verdea lui armură cu stropi de-azur și soare./ [...]/ Părea că e acolo un giuvaer de vis"15. Această individualizare fizică trimite la o ,frumusețe artificială, de bijuterie" ${ }^{\prime 16}$. Plasarea acestuia în orizontul privirii umane, care îi descoperă secretele și îl privește râvnitor, sugerează obiectivizarea șarpelui și risipirea misterului arhetipal.

Balaurul. Nu departe, ca element figurativ de natură reptiliană, se situează balaurul, o fațetă a șarpelui proiectată în fantastic și imaginar, fiind ,legat de stihia văzduhului”"17, amintită precedent. Acesta presupune, în general, o augmentare a caracterului sălbatic, dar și o externalizare a demonilor (interiori), o transpunere în animal a unor probleme mentale. Prezent atât în opera lui Blaga, cât și în cea a lui Voiculescu, acesta trimite la imaginea biblică. Conform lui Ion Pop, acesta „primeşte şi o puternică coloratură folclorică dezvăluind, alături de sensurile negative, şi un înţeles pozitiv." ${ }^{18}$, trimiţând la ideea de univers primordial. Poezia Sfântul Gheorghe bătrân a lui Blaga trimite spre acest univers uitat de timp: „balaurul cu solziimprăştiaţi prin spini [...] din era prea fierbinte ce se sparse."19. Cavalerul trăiește un moment de epifanie, imaginea balaurului trezindu-i un sentiment de dor, de nostalgie faţă timpurile pline de glorie din trecut. Temporalitatea este centrală în text, cadrul în care este pusă creatura evocă o imagine străveche, a luptei glorioase, inaccesibile individului neiniţiat.

Dacă în opera blagiană balaurul este asociat momentelor revelatorii și se găsește într-o dimensiune îndepărtată calitativ, Voiculescu îi conferă o aură mai simplistă, dar care, la rândul ei, trimite la mitul biblic: „să pun piciorul pe grumazul/ Otrăvitorului balaur cu solzi de aur străluciţi” ${ }^{20}$ (În amurg). Observăm că, la fel ca în cazul șarpelui, se pune accent pe elementele ce aparțin de câmpul podoabelor, în dauna mistificării creaturii.

\section{6}


Este vizibil faptul că Blaga utilizează animale și concepte ce aparțin mitologiei creștine în opera sa. Acesta se diferențiază de Vasile Voiculescu prin faptul că le conferă mai degrabă un caracter metafizic, și nu unul plasticizat și plasticizant. Astfel, Blaga mizează pe o valoare simbolică a bestiarului, în timp ce la Voiculescu se limitează la „,popularea unor decoruri”.

Ursul. Dacă șarpele și balaurul reprezintă ipostaze animaliere cu care omul este mereu confruntat, întâlnirea cu aceste figuri având deseori dimensiunea unei lupte, în gândirea magico-religioasă, „niciun alt animal nu este mai asemănător omului decât ursul”21. Mihai Coman plasează acest animal la loc de cinste, susținând că acesta ,posedă și transferă [...] energiile purificatoare ale firii”,22. Blaga evidenţiază puterile apotropaice ale acestui animal în poezia Ursul cu crin: „Spre seară boala iese din casă, din gând și din vine.”23, revitalizând astfel datinile populare. Totodată, este sugerat caracterul ieșit din comun al acestui animal. Acesta este văzut ca un salvator și este glorificat: „I se va-ntinde prescură, pe drumuri stropite cu vin." 24 .

Poezia lui Voiculescu tratează o altă latură a acestui animal. Astfel, opera Gânduri de iarnă prezintă ursul ca animal letargic: „urșii din bârloguri” ${ }^{25}$. Se axează, deci, pe caracterul comun al acestui animal, pe transformările pe care le suferă odată cu schimbarea anotimpului. De asemenea, cadrul spațial în care se află ursul sugerează că ,,voluptatea de a lua contact cu natura este la Voiculescu în primul rând de ordin vizual"26. De asemenea, Voiculescu este cel care, în proză, aduce în discuţie legătura om-urs (în Ultimul Berevoi) sau asumarea de roluri prin măşti, apelând la ritualicul mitologic românesc al costumării unui personaj cu blana de urs.

Cerbul. Un alt animal comun celor doi scriitori este cerbul, ipostaziat drept totem, respectiv pradă, dar simbolizând aceeași virilitate a ursului și, printre altele, regenerarea. Andrei Oișteanu afirmă că acesta este un simbol al ,arborelui vieţii, un transimbol al fecundităţii, al ritmurilor și renovărilor ciclice, al renaşterilor”27, având darul de a călători dintrun tărâm în altul, din concret în ireal. Caracterul psihopomp al acestuia este evidențiat la Blaga în Cerbul cu stea în frunte, unde animalul se transpune în diferite planuri, transcendând limita perceptibilă: „Și-aude, subt naltele,/ unele, altele:/ erele, sferele.” ${ }^{28}$. Pe lângă capacitatea sa de a se conecta cu avaturile civilizației primordiale („Ciulindu-și urechile/ prind străvechile/ rotiri”,29), Blaga îi conturează o latură ancestrală, sugerând refuzul lui de a se desacraliza: „Nu1 mișcă ştiutele/ crânguri cu ciutele./ [...]. Copitele/ sfarmă ispitele." ${ }^{\prime 30}$.

Voiculescu contextualizează cerbul într-un cadru vânătoresc, însă nelipsit de simbolistică. În Amiază pe munte este surprinsă o scenă de vânătoare care trimite la un obicei străvechi conform căruia bărbații, în special pețitorii, erau nevoiţi să sacrifice un cerb pentru 
a-și dovedi vitejia. De asemenea, poezia revitalizează şi o ipoteză mitologică expusă de Mihai Coman, conform căreia ,vânătoare cerbului este sinonimă cu un sacrificiu «de construcție»; ea asigură durata casei concrete, susține în plan mitic, temeinicia clădirii”31. Aici, casa are valoare conotativă, dar convențională, trimițând la cadrul familial, la vatră, la neam și la valorile tradiționale din cadrul acestuia. Această dimensiune arhaică și, într-o oarecare măsură, simbolică, este, însă, constrânsă de punerea în cadru a acestei îndeletniciri. La Blaga se pune accentul pe dimensiunea mitică a cerbului, iar la Voiculescu atenția este îndreptată mai degrabă către procesul de vânătoare: „Zbucnesc pocnete de puști făr' de veste [...]/ Cârduri de hăitași pornesc să coboare" ${ }^{\natural 2}$. Dacă la Blaga accentul cade asupra măreției animalului, la Voiculescu accentul cade asupra acțiunii, asupra dinamicului. Totodată, cel din urmă alege să introducă planul uman, desacralizând cadrul poetic.

O asemănare, totuși, se stabilește între abordările celor doi, și anume construcția cadrului exterior. Ambii aleg un topos natural (creste, crânguri, dumbrăvi), pe care îl învăluie în mister. Elena Zaharia-Filipaș confirmă această ipoteză: „ca în lirica lui Blaga, natura lui Voiculescu se melancolizează”, la amândoi ,liniștea [devine] neverosimil palpabilă"33. Cadrul natural în poezia blagiană trimite la o imagine statică și plină de profunzime, patronată de tihnă (,Prin ceață când lunecă”34). Chiar verbul a luneca trimite atât la delicatețea cerbului, în contrast cu brutalitatea cu care este asociat în cadrul profan, cât și la o dimensiune lipsită de dinamism. Această atmosferă se regăsește și la Voiculescu, după ce momentul tensionat al vânătorii este depășit („Pe-albastre singurătăți tăcerea-i iar de piatră,/ Liniștea - de aur”35), liniștea primordială fiind recăpătată.

Calul. Mult mai comun, dar poate la fel de impetuos, prin statură și agilitate, apare calul. Conform credinţelor universale, dar și românești, calul este un ,prevestitor al căilor oamenilor spre «celălalt tărâm»" ${ }^{36}$. Această atribuție a lui este amintită în numeroase basme și povestiri românești. Blaga valorizează această semnificaţie, însă o distorsionează într-un mod metaforic. În acest sens, în poezia Mânzul, animalul simbolizează trecerea dintr-o etapă a vieții în alta: „Zace în grajd, arde ca focul.”37. Transfigurarea sa sugerează o dimensiune existențială alternativă, apropiată funebrului.

Dacă Blaga metaforizează mitul solar amintit mai sus, Voiculescu valorizează credința folclorică, prin care se ,,asociază calul cu feciorul și fecioria”38. În acest context, calul este socotit ca fiind ajutorul luptătorului, care îl folosește pentru a-și dovedi vitejia în grupul sociocultural căruia îi aparține. Această ipostază a calului apare în poezia În amurg. Fiind învins, voinicul conchide: „Murit-a calul meu năprasnic și ruptă-i pala mea vitează ${ }^{\prime 39}$. La fel ca în

\section{8}


cazul altor animale prezentate anterior, se observă tendinţa lui Voiculescu de a materializa animalul în cadre denotative, folosindu-se cu precădere de elementele folclorice.

Inorogul. Pe lângă metaforizarea calului, Blaga include în opera sa inorogul, respectiv unicornul, ca înrudiri ale acestuia. Potrivit unei legende românești, dispariţia inorogului se explică prin neascultarea lui față de Noe. Caracterul său răzvrătit este sugerat de-a lungul mai multor opere blagiene prin faptul că acesta încearcă să atingă valorile absolute: „Pe țărm unicornul, o clipă cât anul,/ se-nfruntă-n poveste cu oceanul"40. Acesta este un animal special, deosebit de celelalte, care își are prezența în întreaga creație, aspect evidenţiat în $\mathrm{Ce}$ aude unicornul. Poezia sugerează omniprezența spirituală a acestei creaturi la nivelul mai multor planuri, în dauna dispariţiei sale materiale: uman, ideal, spaţio-temporal. El „,aude” dincolo de lucrurile lumești, pătrunzând esența existențială. Practic, modalitatea de figurare a acestui animal rezumă întreaga poetică a bestiarului blagian și diferențierea acesteia față de lirica lui Voiculescu. Dacă unicornul nu aparține fundamental spațiului cultural tradițional românesc, fiind deseori un ,import” cultural inclusiv la Cantemir, trimițând la imaginea lui Pegasus din mitologia greacă, procesul său de adaptare în viziune blagiană înseamnă purificare, idealizare. Excepționalismul său, inclusiv prin sublimarea sexualității, marchează simbolic transferul bestiarului în planul intelectual al ideii.

\section{Concluzie}

În concluzie, la nivelul creațiilor poetice ale celor doi scriitori se pot repera aceleași animale, însă modurile de abordare a acestora diferă. La Blaga ,animalitatea capătă o notă de suavitate și puritate" ${ }^{\prime 1}$. El revitalizează elemental banal, animalic, conferindu-i atribute nebănuite, misterioase. Voiculescu, pe de altă parte, accentuează fondul primar, concret al animalelor, lăsând la o parte punerea lor într-un plan superior. La el, necuvântătoarele sunt proiectate ,într-un timp îndepărtat al civilizațiilor pastorale” ${ }^{״ 2}$. Scenariile în care sunt plasate animalele sunt adesea brutale (vânătoarea) sau comune. Așadar, deși fundamentul folcloricomitic este comun celor doi, reprezentările bestiarului se limitează la un panpastoralism ${ }^{43}$ la Voiculescu, în care animalul este asimilat decorului, la fel ca ,toate aspectele universului văzut"44, în timp ce Blaga abstractizează și transferă animalierul în planul simbolic al satuluiidee sau în contexte revelatorii. 


\section{Bibliografie}

Blaga, Lucian, Poezii, Editura Cartea Românească, București, 1982.

Coman, Mihai, Bestiarul mitologic românesc, Editura Fundației Culturale Române, București, 1996.

Evseev, Ivan, Enciclopedia semnelor și simbolurilor culturale, Editura Amarcord, Timișoara, 1999.

Oișteanu, Andrei, Grădina de dincolo. Zoosophia, Editura Dacia, Cluj-Napoca, 1980.

Pop, Ion, Lucian Blaga - Universul liric, Editura Cartea Românească, București, 1981.

Taloș, Ion, Gândirea magico-religioasă la români. Dicționar, Editura Enciclopedică, București, 2001.

Todoran, Eugen, Lucian Blaga. Mit. Poezie. Mit poetic, Editura Grai și suflet - Cultura națională, București, 1997.

Vianu, Tudor, Alegorism, în Opere, vol. 5: Studii de stilistică, Ediție îngrijită de Sorin Alexandrescu, Matei Călinescu şi Gelu Ionescu, Antologie, note și postfață de Gelu Ionescu, Editura Minerva, București, 1975, p. 549-558.

Voiculescu, Vasile, Integrala operei poetice, Ediție îngrijită și prefaţă de Roxana Sorescu, Editura Anastasia, București, 1999.

Zaharia-Filipaș, Elena, Introducere în opera lui Vasile Voiculescu, Editura Minerva, București, 1980.

\footnotetext{
${ }^{1}$ Andrei Oișteanu, Grădina de dincolo. Zoosophia, Editura Dacia, Cluj-Napoca, 1980, p. 138.

${ }^{2}$ Idem, ibidem.

${ }^{3}$ Idem, ibidem, p. 141.

${ }^{4}$ Ivan Evseev, Enciclopedia semnelor și simbolurilor culturale, Editura Amarcord, Timişoara, 1999, p. 447.

${ }^{5}$ Lucian Blaga, Poezii, Editura Cartea Românească, București, 1982, p. 169.

${ }^{6}$ Mihai Coman, Bestiarul mitologic românesc, Editura Fundației Culturale Române, București, 1996, p. 99.

${ }^{7}$ Ion Mușlea, Ovidiu Bârlea, Tipologia folclorului (din răspunsurile la chestionarele lui B. P. Hasdeu), Editura Minerva, București, 1970, p. 186 apud Mihai Coman, Bestiarul mitologic românesc, Editura Fundației Culturale Române, București, 1996, p. 209.

${ }^{8}$ Vasile Voiculescu, Integrala operei poetice, Ediție îngrijită și prefață de Roxana Sorescu, Editura Anastasia, București, 1999, p. 338.

${ }^{9}$ Ivan Evseev, op. cit., p. 447.

${ }^{10}$ Lucian Blaga, op. cit., p. 31.

${ }^{11}$ Vasile Voiculescu, op. cit., p. 327.

${ }^{12}$ Lucian Blaga, op. cit., p. 24.

${ }^{13}$ Idem, ibidem.

${ }^{14}$ Idem, ibidem, p. 92.

${ }^{15}$ Vasile Voiculescu, op. cit., p. 555.

${ }^{16}$ Elena Zaharia-Filipaș, Introducere în opera lui Vasile Voiculescu, Editura Minerva, București, 1980, p. 52.

${ }^{17}$ Ivan Evseev, op. cit., p. 447.

${ }^{18}$ Ion Pop, Lucian Blaga - Universul liric, Editura Cartea Românească, București, 1981, p. 183.

${ }^{19}$ Lucian Blaga, op. cit., p. 184.

${ }^{20}$ Vasile Voiculescu, op. cit., p. 118.

${ }^{21}$ Ion Taloș, Gândirea magico-religioasă la români. Dicționar, Editura Enciclopedică, București, 2001, p. 179.

${ }^{22}$ Mihai Coman, op. cit., p. 145.
} 
${ }^{23}$ Lucian Blaga, op. cit., p. 139.

${ }^{24}$ Idem, ibidem.

${ }^{25}$ Vasile Voiculescu, op. cit., p. 555.

${ }^{26}$ Elena Zaharia-Filipaș, op. cit., 53.

${ }^{27}$ Andrei Oişteanu, op. cit., p. 48.

${ }^{28}$ Lucian Blaga, op. cit., p. 365.

${ }^{29}$ Idem, ibidem.

${ }^{30}$ Idem, ibidem., p. 364.

${ }^{31}$ Mihai Coman, op. cit., p. 135.

${ }^{32}$ Vasile Voiculescu, op. cit., p. 268.

${ }^{33}$ Elena Zaharia-Filipaş, op. cit., p. 59.

${ }^{34}$ Lucian Blaga, op. cit., p. 364.

${ }^{35}$ Vasile Voiculescu, op. cit., p. 269.

${ }^{36}$ Eugen Todoran, Lucian Blaga. Mit. Poezie. Mit poetic, Editura Grai și suflet - Cultura naţională, București, 1997, p. 287.

${ }^{37}$ Lucian Blaga, op. cit., p. 181.

${ }^{38}$ Mihai Coman, op. cit., p. 51.

${ }^{39}$ Vasile Voiculescu, op. cit., p. 119.

${ }^{40}$ Lucian Blaga, op. cit., p. 163.

${ }^{41}$ Ion Pop, op. cit., p. 180.

${ }^{42}$ Elena Zaharia-Filipaș, op. cit., p. 48.

${ }^{43}$ Tudor Vianu, Alegorism, în Opere, vol. 5: Studii de stilistică, Ediție îngrijită de Sorin Alexandrescu, Matei Călinescu şi Gelu Ionescu, Antologie, note și postfață de Gelu Ionescu, Editura Minerva, București, 1975, p. 549558, aici p. 554.

${ }^{44}$ Idem, ibidem. 